\title{
Determining Gas Sampling Timelines for Estimating Emissions in Small Chamber Incubation Experiments
}

\author{
D.H. Nguyen ${ }^{1,2 *}$ P.R. Grace ${ }^{1}$, C. Scheer ${ }^{1}$ and D. Rowlings ${ }^{1}$ \\ 'Queensland University of Technology, Brisbane, QLD, Australia \\ ${ }^{2}$ Sugarcane Research Institute, Binh Duong, Vietnam
}

\begin{abstract}
A laboratory experiment was set up in small chambers for monitoring greenhouse gas emissions and determining the most suitable time for sampling. A six-treatment experiment was conducted, including a one week pre-incubation and a week for incubation. Timelines for sampling were 1, 2, 3, 6 and 24 hours after closing the lid of the incubation chambers. Variation in greenhouse gas fluxes was high due to the time of sampling. The rates of gas emissions increased in first three hours and decreased afterward. The rates of greenhouse gas emissions at 3 hours after closing lids was close to the mean for the 24-h period.
\end{abstract}

Keywords: - biochar, chamber, Ferrosol soil, incubation, sampling

\section{INTRODUCTION}

Research on greenhouse gas (GHG) emissions in agricultural science has been motivated in recent decades by mitigating climate change and global warming. This is because GHG emissions have an impact on the broader environment (through global warming) as well as its contribution to carbon and nutrient losses. To evaluate GHG emissions (carbon dioxide, methane and nitrous oxide), both laboratory and field experiments are required. Laboratory experiments play an important role in researching GHG emissions as they provide information on processes controlling emissions under controlled temperature and moisture conditions. This type of research can be conducted in incubators and glasshouses.

In laboratory incubations, $0.5 \mathrm{~L}$ glass chambers $[\underline{1}, \underline{2}], 1.0 \mathrm{~L}$ []ㅡ or $5.0 \mathrm{~L}$ glass jars [4] (hereafter "chambers") have been used for soil incubation which are sealed and gas samples taken from the chambers. The volume of the chambers varies due to the weight of soil that is used in the experiments and the purpose of the research. For example, a large amount of soil provides less variability, as well as the ability to take soil subsample for analysis during the incubation.

For the timing of gas sampling, different timelines have been used for their measurement of GHG emissions. If the incubation time is too long, the concentration of emissions will be saturated reducing oxygen in the headspace which affects the microbial activity which produces carbon dioxide and nitrous oxide. Gas samples have been taken after closing for a half hour [ $[\underline{5-7}]$, one hour [ $\underline{3-6}, \underline{8}]$, two hours $[\underline{2}, \underline{9}]$ and four hours [10]. The time for sampling chosen by different authors has not following any previous studies. It has led to confusion for other researchers setting up new experiments. The aim of this study is to determine the suitable timeline for sampling in small chamber laboratory incubations.

\section{MATERIALS AND METHODS}

Soil was collected from Wollongbar $\left(28^{\circ} 49^{\prime} \mathrm{S}, 153^{\circ} 25^{\prime} \mathrm{E}\right)$, NSW, Australia. This soil is classified as red Ferrosol [11]. Top soil was collected from the cultivated surface $(0-20 \mathrm{~cm})$, air-dried and sieved through a 2$\mathrm{mm}$ stainless steel mesh. It after that was stored in fridge at $4^{\circ} \mathrm{C}$ until used. Soil bulk density was $1.02 \mathrm{~g} \mathrm{~cm}^{-3}$

Biochar used in this experiment was produced from rice husks after pyrolysis and supplied by Barmac Industries Pty Ltd. Chemical properties of rice husk biochar (hereafter biochar) are listed as total C (\%) 46.5, N (\%) $0.62, \mathrm{pH}\left(1: 5 \mathrm{H}_{2} \mathrm{O}\right) 9.1$ and $\mathrm{CEC} 17.9(\mathrm{cmol} / \mathrm{kg})$ [9]

A laboratory experiment was set up with six treatments with and without biochar applied at the equivalent of 0,20 and 50 tonnes biochar ha ${ }^{-1}$ and two water contents (60 and $90 \%$ water-filled pore space ). Water-filled pore space (WFPS) is calculated as:

$$
\text { WFPS }(\%)=\frac{\text { GWC x BD }}{1-\frac{\mathrm{BD}}{2.65}} \quad \begin{aligned}
& \text { where: } \\
& \text { - GWC: gravimetric water content }(\%)
\end{aligned} \quad \begin{aligned}
& - \text { BD: soil bulk density }\left(\mathrm{g} / \mathrm{cm}^{3}\right) \\
& \text { - } 2.65 \text { assumes the soil particle density }\left(\mathrm{g} / \mathrm{cm}^{3}\right)
\end{aligned}
$$

The six treatments (with four replicates) were (i) 0 biochar 60\% WFPS, (ii) 0 biochar $90 \%$ WFPS, (iii) $20 \mathrm{t}$ biochar 60\% WFPS, (iv) 20t biochar 90\% WFPS, (v) 50t biochar 60\% WFPS, and (vi) 50t biochar $90 \%$ WFPS. 
Approximately $225 \mathrm{~g}$ air-dried soil $\left(200 \mathrm{~cm}^{3}\right.$ equivalent) was well mixed with the given amount of biochar and re-packed into a PVC core $(25 \mathrm{~cm}$ high, $5.05 \mathrm{~cm}$ internal diameter). The cores were placed in a 1-L glass chamber (jar). The soil was treated with deionized water to adjust water content to $60 \%$ WFPS. All the chambers were pre-incubated at $25^{\circ} \mathrm{C}$ for seven days to stabilize the activities of micro-organisms. After preincubation, the water content was adjusted to 60 or $90 \%$ WFPS (i.e. near saturation), respectively by adding deionized water and checked regularly every 3 days by weighing. The rate of biochar was applied based on the surface area $\left(1 \mathrm{ha}=10,000 \mathrm{~m}^{2}\right)$ with a core surface area is $20 \mathrm{~cm}^{2}$.

The headspace air was observed after 1, 3 and 7 days incubation. Preparing for gas sampling, the jars were capped by a septum lids. Samples were taken at 1, 2, 3, 6, and 24 hours after the lid closure for three days by using a gas-tight syringe inserted through the rubber septum. After sampling, the jars were opened for air exchange. Gas samples taken in the syringe were immediately transferred to an evacuated exetainer (Labco Ltd, Buckinghamshire, UK).

Concentrations of $\mathrm{N}_{2} \mathrm{O}$ and $\mathrm{CO}_{2}$ was measured by a gas chromatograph (Shimadzu, Japan) equipped with two detectors. $\mathrm{N}_{2} \mathrm{O}$ was detected by electron capture detector (ECD) and $\mathrm{CO}_{2}$ was detected by hydrogen flame ionization detector (FID). Flux rates of $\mathrm{N}_{2} \mathrm{O}$ and $\mathrm{CO}_{2}$ were calculated using equation 1 and 2 which were described in van Zwieten et al. [4].

\section{RESULTS AND DISCUSSION}

The fluxes of $\mathrm{CO}_{2}$ and $\mathrm{N}_{2} \mathrm{O}$ varied during the time of sampling (Figure 1). In Day 1 and Day 3, the fluxes were reducing for every hour. The fluxes of greenhouse gases could be distinguished into two groups. The emissions were low in the low water content (60\% WFPS) meanwhile the higher water content $(90 \%$ WFPS) emitted the higher GHG emissions.

At Day 7, the concentration of $\mathrm{CO}_{2}$ was similar trend to other days before but the $\mathrm{N}_{2} \mathrm{O}$ flux increased in the first 3 hours and then reduced in the sixth hour and continuously reduced until the $24^{\text {th }}$ hour.
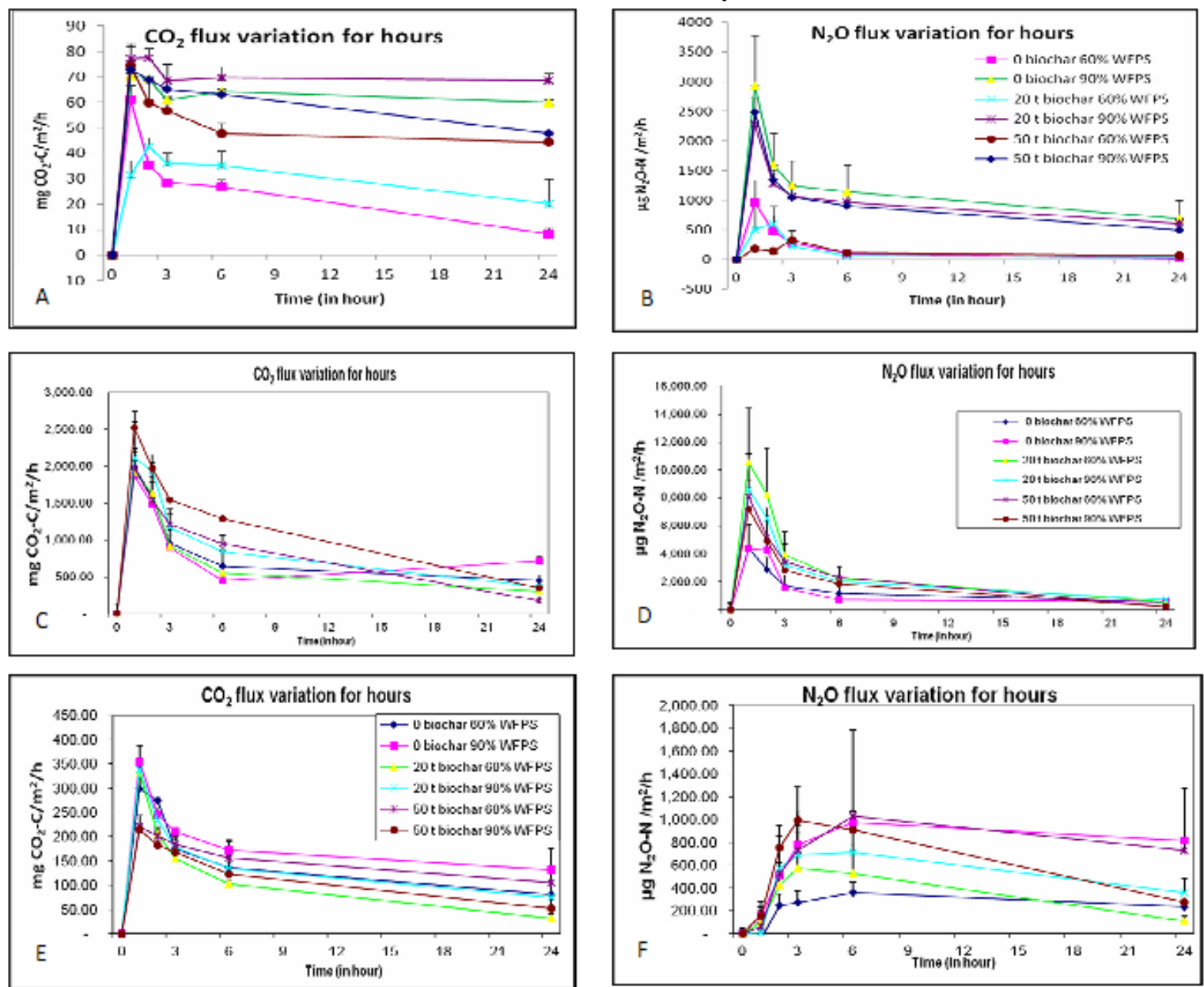

Figure 1. Comparison GHG fluxes for one, three and seven days after incubating at $25^{\circ} \mathrm{C}$. Error bars present one standard error. Note: A\&B present Day 1, C\&D express Day 3 and E\&F show Day 7.

For $\mathrm{CO}_{2}$ emission, it changed from $31-74 \mathrm{mg} \mathrm{CO} \mathrm{CO}_{2}-\mathrm{C} / \mathrm{m}^{2} / \mathrm{h}$ at one hour to $8-68 \mathrm{mg} \mathrm{CO}_{2}-\mathrm{C}^{2} / \mathrm{m}^{2} / \mathrm{h}$ at 24 hours in Day 1 (referred in Figure 1). The $\mathrm{N}_{2} \mathrm{O}$ flux rate dropped from 179-2,929 $\mu \mathrm{g} \mathrm{N} \mathrm{N}_{2} \mathrm{O}-\mathrm{N} / \mathrm{m}^{2} / \mathrm{h}$ in the first 
hour to $27-691 \mu \mathrm{g} \mathrm{N} \mathrm{N}_{2} \mathrm{O}-\mathrm{N} / \mathrm{m}^{2} / \mathrm{h}$ at 24 hours in Day 1 . The flux rates at three hours were similar to the mean of the 24-h period incubation.

In general, the rates of $\mathrm{CO}_{2}$ and $\mathrm{N}_{2} \mathrm{O}$ emissions were higher in the $90 \%$ WFPS treatments than those of $60 \%$ WFPS. This is similar to the result of Dobbie and Smith [10]. Moreover, the $\mathrm{N}_{2} \mathrm{O}$ emissions in Day 3 (Figure $1 \mathrm{C} \& \mathrm{D}$ ) increased higher in Day 1 and Day 7 which supported the result from Singh et al. []].

The relationships between sampling time and greenhouse gas emissions were negatively correlated (Table 1). The $\mathrm{R}^{2}$ were more than 0.5 to 0.8 (except 0.31 in the 0 biochar $90 \%$ WFPS). When the time of closure was too long, the gas emissions did not increase. This may be due to saturation of gas in the headspace and low oxygen concentrations affecting microbial activities.

Sampling chamber headspace at three hours after closure of the lids gave the best results for estimating gas emissions. The timelines for sampling would be implied in the studies with small chamber from $0.5 \mathrm{~L}$ to $5 \mathrm{~L}$ in the incubation condition.

Table 1. Relationship between time of sampling and GHG flux rates. * The regressions $\left(\mathrm{R}^{2}\right)$ are significant at $\mathrm{P}<0.05$.

\begin{tabular}{cllllll}
\hline & \multicolumn{2}{l}{$\mathrm{CO}_{2}$ emissions } & \multicolumn{2}{l}{$\mathrm{N}_{2} \mathrm{O}$ emissions } \\
Treatments & Slope & Intercept & $\mathrm{R}^{2^{*}}$ & Slope & Intercept & $\mathrm{R}^{2^{*}}$ \\
\hline 0 t biochar 60\% WFPS & -19.32 & 588.52 & 0.54 & -45.01 & $1,229.0$ & 0.53 \\
0 t biochar 90\% WFPS & -12.76 & 548.27 & 0.31 & -57.42 & $1,902.2$ & 0.50 \\
20 t biochar 60\% WFPS & -21.28 & 574.50 & 0.58 & -117.22 & $2,751.9$ & 0.59 \\
20 t biochar 90\% WFPS & -23.63 & 686.06 & 0.66 & -98.49 & $2,683.1$ & 0.59 \\
50 t biochar 60\% WFPS & -23.20 & 634.05 & 0.83 & -79.94 & $2,123.0$ & 0.71 \\
50 t biochar 90\% WFPS & -27.86 & 782.85 & 0.82 & -95.84 & $2,451.9$ & 0.68 \\
\hline
\end{tabular}

\section{CONCLUSIONS}

This is the first research to examine the effect of sampling time on GHG emissions in laboratory incubations. Using small $(1.0 \mathrm{~L})$ chambers in laboratory incubations, flux rates were estimated after headspace sampling at 1, 2, 3, 6 and 24 hours. After lids were closed for three hours was determined the best choice for gas sampling.

Acknowledgements We gratefully acknowledge funding from VIED-QUT scholarship. We thank Lukas van Zwieten and Stephen Kimber from Industry and Investment NSW for their supports and Sugarcane Research Institute (Vietnam) for excellent assistance.

\section{REFERENCES}

[1] Peng, X., et al., Temperature- and duration-dependent rice straw-derived biochar: Characteristics and its effects on soil properties of an Ultisol in southern China. Soil \& Tillage Research, 2011. 112(2): p. 159-166.

[2] Huang, Y., et al., Nitrous oxide emissions as influenced by amendment of plant residues with different C:N ratios. Soil Biol. Biochem., 2004. 36: p. 973-981.

[3] Velthof, G.L., P.J. Kuikman, and O. Oenema, Nitrous oxide emission from soil amended with crop residues. Nutr Cycl Agroecosyt, 2002. 62: p. 249-61.

[4] van Zwieten, L., et al., Influence of biochar on flux of $\mathrm{N}_{2} \mathrm{O}$ and $\mathrm{CO}_{2}$ from Ferrosol. Soil Research, 2010. 48: p. 555568.

[5] Inselsbacher, E., et al., Greenhouse gas fluxes respond to different $N$ fertilizer types due to altered plant-soil-microbe interactions. Plant and Soil, 2011. 343(1-2): p. 17-35.

[6] Singh, B.P., et al., Influence of biochar on nitrous oxide emissions and nitrogen leaching from two contrasting soils. Environ. Qual., 2010. 39: p. 1224-35.

[7] Guo, Z.L., et al., Crop residue effect on crop performance, soil $\mathrm{N}_{2} \mathrm{O}$ and $\mathrm{CO}_{2}$ emissions in alley cropping systems in subtropical China. Agroforestry Systems, 2009. 76: p. 67-80.

[8] Weier, $\mathrm{K}$., $\mathrm{N}_{2} \mathrm{O}$ and $\mathrm{CH}_{4}$ emission and $\mathrm{CH}_{4}$ consumption in a sugarcane soil after variation in nitrogen and water application. Soil Biol. Biochem., 1999. 31(14): p. 1931-41.

[9] Wang, J., et al., Effects of biochar addition on $\mathrm{N}_{2} \mathrm{O}$ and $\mathrm{CO}_{2}$ emission from two paddy soil. Biol. Fertil. Soils, 2011. 51: p. 125-134.

[10] Dobbie, K. and K. Smith, The effects of temperature, water-filled pore space and land use on $\mathrm{N}_{2} \mathrm{O}$ emissions from an imperfectly drained gleysol. Eur. J. Soil Sci., 2001. 52: p. 667-673.

[11] Isbell, R.F., The Australian Soil Classification, ed. Revised. 2002, Victoria: CSIRO Plublishing. 